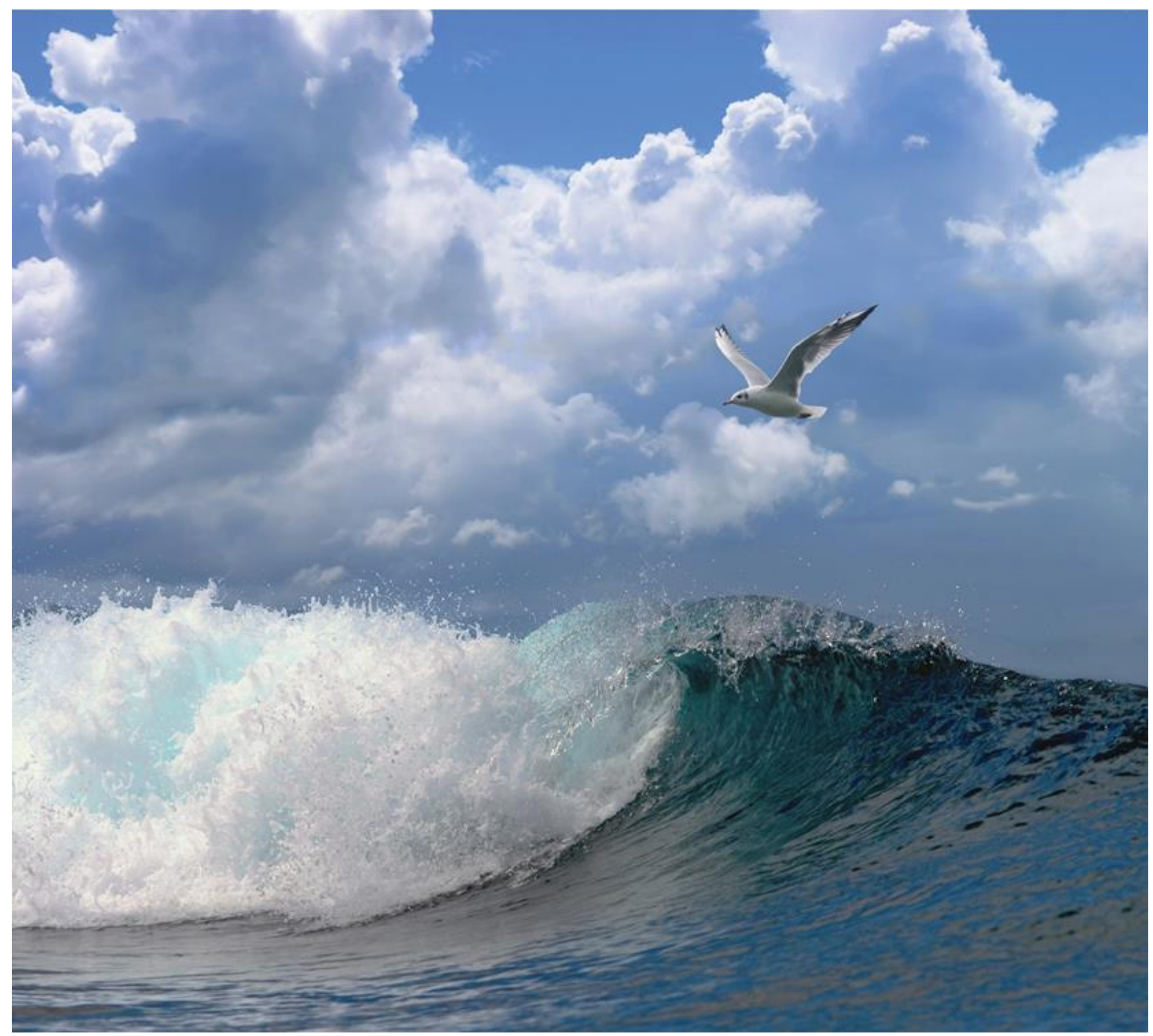

\title{
Pelagic blue whiting trawl innovation:
} hake grid 


\section{Pelagic blue whiting trawl innovation: hake grid}

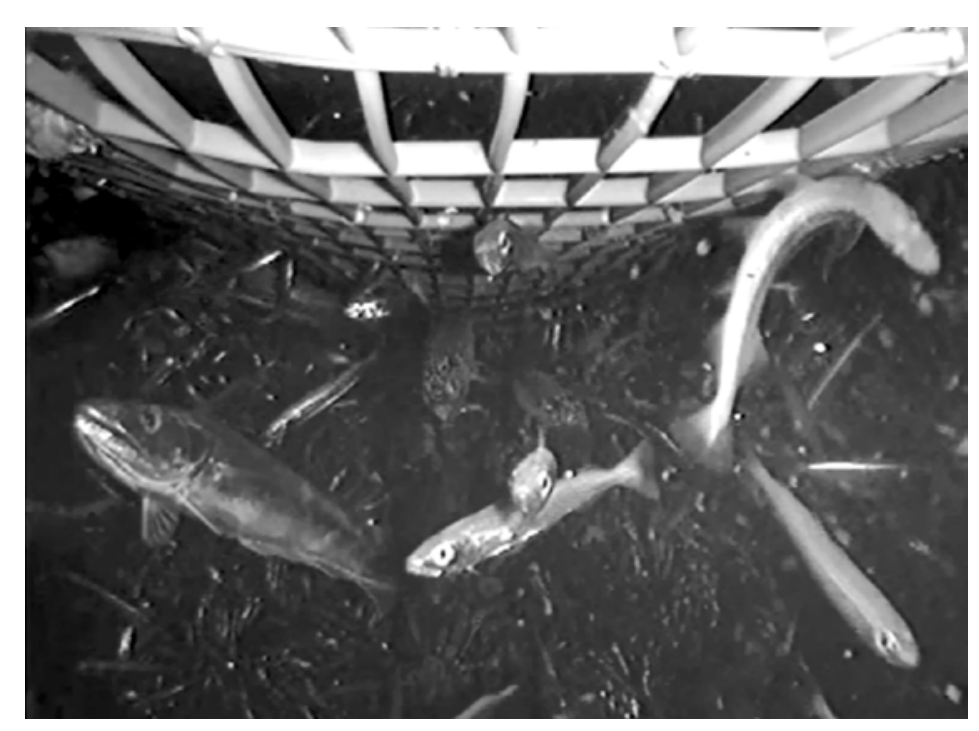

Author(s):

J. van Rijn

A.T.M. van Helmond

P. Molenaar

Publication date: $\quad 16^{\text {th }}$ of October 2017

Wageningen Marine Research

Ijmuiden, October 2017

Wageningen Marine Research report C080/17 
Van Rijn, J. van Helmond, A.T.M. Molenaar, P., 2017. Pelagic blue whiting trawl innovation: hake grid. Wageningen, Wageningen Marine Research (University \& Research centre), Wageningen Marine Research report C080/17. 19 pp.; 2 tab.

Keywords: sorting grid, hake, trawl innovation.

Date $16^{\text {th }}$ of October 2017

Client: $\quad$ Pelagic Freezer-trawler Association (PFA)

Attn.: Martin Pastoors

Louis Braillelaan 80

2719 ED, Zoetermeer

This report can be downloaded for free from https://doi.org/10.18174/425088

Wageningen Marine Research provides no printed copies of reports.

Wageningen Marine Research is ISO 9001:2008 certified.

Photo cover: M. Pastoors

(C) 2016 Wageningen Marine Research Wageningen UR

Wageningen Marine Research The Management of Wageningen Marine Research is not responsible for resulting institute of Stichting Wageningen damage, as well as for damage resulting from the application of results or Research is registered in the Dutch research obtained by Wageningen Marine Research, its clients or any claims traderecord nr. 09098104, BTW nr. NL 806511618 related to the application of information found within its research. This report has been made on the request of the client and is wholly the client's property. This report may not be reproduced and/or published partially or in its entirety without the express written consent of the client. 


\section{Contents}

$\begin{array}{lr}\text { Summary } & 4\end{array}$

1 Introduction $\quad 5$

$\begin{array}{llr}2 & \text { Assignment } & 6\end{array}$

$3 \quad$ Materials and Methods $\quad 7$

$\begin{array}{lll}3.1 & \text { Pelagic trawl } & 7\end{array}$

$\begin{array}{ll}3.2 & \text { Sorting grid design }\end{array}$

3.3 Camera setup $\quad 9$

$\begin{array}{llr}3.4 & \text { Field notes and other observations } & 9\end{array}$

3.5 Manual video analysis $\quad 10$

3.5.1 Sample selection $\quad 11$

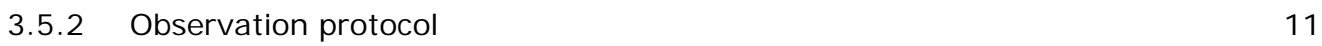

$4 \quad$ Results $\quad 12$

$\begin{array}{llr}4.1 & \text { Sorting grid } & 12\end{array}$

$\begin{array}{lll}4.2 & \text { Hake (Merluccius merluccis) } & 13\end{array}$

$\begin{array}{lll}4.3 & \text { Blue whiting (Micromesistius poutassou) } & 13\end{array}$

4.4 Mackerels (Scombridae) 14

4.5 Saithe (Pollachius virens) 14

$5 \quad$ Conclusions and recommendations $\quad 15$

$6 \quad$ Quality Assurance $\quad 17$

$\begin{array}{lr}\text { J ustification } & 18\end{array}$ 


\section{Summary}

The implementation of the EU landing obligation has strong implications for the fisheries sector. The landing obligation even poses a challenge for the pelagic sector, which is generally described as a single species fishery with relatively low bycatch rates. In the blue whiting fishery the limited quota available for hake (Merluccius merluccis) is problematic because the by-catch of this species cannot always be avoided.

Therefore the Pelagic Freezer-trawler Association (PFA) aims to reduce the by-catch of hake with the introduction of sorting grids. The Nordsøtrawl sorting grid was tested on board of the Frank Bonefaas ( $\mathrm{SCH} 72)$ and the functioning was recorded with the DeepWater Camera Unit from JT electric Ltd. The footage was reviewed by Wageningen Marine Research who assessed the effectiveness of the sorting grid and studied fish behaviour in and around the selective device.

The main project objective was:

1. To develop and optimise effective sorting grids in pelagic trawls that limit the bycatch of large hake.

A selective device, tunnel and sorting grid, was tested in a standard mid-water pelagic trawl for blue whiting. The camera was placed on three different positions in (2) and outside (1) the net to observe all aspects of the selective device. During the sea trials several adjustments were made to the trawl in order to improve functioning of the selective device. The footage per haul was stored in clips of 5 minutes each by the camera system. Per haul $10 \%$ of the fishing footage was reviewed by a scientific observer, with a minimum of three video clips of 5 minutes. The video clips that had to be sampled were selected with a randomizer, a total of 33 clips were sampled.

The tested selective device does not cause any problem for the strong swimming mackerels and saithe. Blue whiting are reasonable swimmers and are able to prevent getting stuck against the netting but a reasonably large part does not swim through the grid but escape from the trawl via the exit-hole. Hake are poor swimmers therefore many individuals end up getting stuck in the netting before they get to the grid or exit-hole. The selective device shows potential to reduce the by-catch of hake but it requires some additional improvements before it can effectively function in practice.

For the selective device to be more effective hake need a smooth and unobstructed path to the exithole. Blue whiting their position needs to be adjusted so that all specimens initially get pushed to the grid instead of the lower part of the tunnel where they are immediately pushed to the exit-hole. Observations from the selective devices showed that several improvements could be made. If the sorting grid would be made wider and extended until lower panel of the trawl or instead extend the grid and taper the tunnel towards the grid, the probability of hake successfully escaping and the chance that blue whiting find their way through the grid should increase. This together with adjustments to the selective device in order to keep the sorting grid at the intended angle should increase the effectiveness of the grid. In addition, it could be worth exploring the difference in behaviour between hake and blue whiting by adding floating ropes/strings or a guiding panel in the grid section of the tunnel. The loose floating ropes are intended to trigger blue whiting their escape response and should give them a greater chance of making it through the grid. While the guiding panel 'forces' all individuals closer to the grid, thereby increasing the chance of blue whiting swimming through the grid and into the codend. Both options require careful design to prevent hake entanglement. 


\section{$1 \quad$ Introduction}

The implementation of the EU landing obligation has strong implications for the fisheries sector: Fishers are obliged to land all catches of species that are subject to the landing obligation, catch weights need to be recorded and counted against quota. Even for the pelagic sector, which is generally described as a single species fishery with relatively low bycatch rates, the landing obligation has a significant impact.

This report focuses on the pelagic trawl fishery for blue whiting (Micromesistius poutassou) and the bycatch of hake (Merluccius merluccis) within this fishery. Although hake by-catch amounts to merely several percent of the total catch, in practice this can add up to as much as 1.5 tonnes per haul. The by-catch of in specific large individuals $(>60 \mathrm{~cm})$ is problematic, since the damage inflicted by the fish pump, that is used to empty the codend on deck, makes the larger hake unsuitable for human consumption and therefore unprofitable. In addition, the quota for hake is limited; the necessary extra quota is not always available and hiring or swopping quota for other species is either expensive or unfavourable.

When targeting blue whiting, the by-catch of hake cannot always be avoided. Therefore the Pelagic Freezer-trawler Association (PFA) wishes to reduce the bycatch of large hake by installing sorting grids inside the trawl. The principal idea of this sorting grid is to separate larger specimens, e.g. large hake, from the smaller individuals, e.g. blue whiting and small hake, and release the larger specimens from the trawl through an exit-hole. As a consequence, the bycatch is reduced, or avoided, and less quota is needed to cover the unprofitable catch of large hake.

Innovation of the fishing industry to enhance the implementation of the landing obligation is supported by the Dutch government. To be able to investigate and test technical innovations, scientific quota is made available to compensate for a potential loss of revenue, under the condition that a scientific institute is involved in supervising the process. In this case, Wageningen Marine Research (WMR) was commissioned to be the scientific supervisor of the project.

During a two weeks trail in May 2017 the functioning of the sorting grid was recorded with an underwater camera. The footage supposedly was to be analysed with an automated system developed by the French research Institute IFREMER. However, during the sea trials multiple difficulties (e.g. unstable footage) were encountered that made it impossible to use this method to analyse the footage. Instead a manual qualitative analysis was conducted by WMR to evaluate the effectiveness of the sorting grid. During this analysis behaviour of blue whiting and hake in relation to the different sorting grid configurations were reviewed. In addition, the behaviour of other species in the catch, mackerels and saithe, was described. 


\section{Assignment}

The main project objective was to develop and optimise effective sorting grids in pelagic blue whiting trawls that limit the bycatch of (large) hake.

WMR was assigned to review footage of underwater recordings and make, based on observation, a qualitative analysis of the efficiency of the sorting grid in relation to fish behaviour in the trawl and interaction with selectivity devices in order to:

- Give an indication of the potential of the sorting grid in general

- Review the efficiency of the sorting grid in separating hake and blue whiting based on differences in behaviour between the two species

- Advice on improving the sorting grid based on observed behaviour of hake, blue whiting and relevant observations of other species, if available 


\section{$3 \quad$ Materials and Methods}

The sea trials were done in ICES area 6.a during weeks 18 and 19 of 2017 on board of the "Frank Bonefaas" ( $\mathrm{SCH} 72$ ) under guidance of the chief science officer of the Pelagic Freezer-trawler Association.

\subsection{Pelagic trawl}

During the sea trials a mid-water pelagic trawl, a cone-shaped net that is spread by pelagic trawl doors, was used. This is the common gear to target blue whiting. Two different net types (trawls), consisting of different materials, were used during these trails, a dyneema trawl and a heavier nylon trawl. The vertical opening of the trawl varied between 60 to 78 meters and the horizontal opening between 130 to 144 meters. The mesh in the codend was $40 \mathrm{~mm}$. The fishing depth was between 200 and 420 meters. When emptying the codend, it remains in the water and to get the catch on board a pump and a hose, with a diameter of $35 \mathrm{~cm}$, is inserted in the codend while the catch is pumped on the deck.

\subsection{Sorting grid design}

The principle function of the sorting grid is to separate larger specimens from the smaller individuals and release the larger specimens through an exit-hole from the trawl, while smaller individuals, passing the sorting grid, end up being retained the codend. The selective device (hake excluding device) is constructed in the codend part of the trawl with a tunnel that guides the fish to a grid (figure 3.1). The tunnel is made of $160 \mathrm{~mm}$ T90 mesh and a sorting grid by Nordsøtrawl (figure 3.2) was used with the dimensions of 1 by $3.5 \mathrm{~m}(\mathrm{WxH})$ and 5.5 by $16 \mathrm{~cm}(\mathrm{WxH})$ bar spacing, see figure 3.3 on the next page for scale. The grid was positioned at a 50 degree angle. Below the sorting grid the last part of the tunnel consisted of a fine mesh piece of netting.

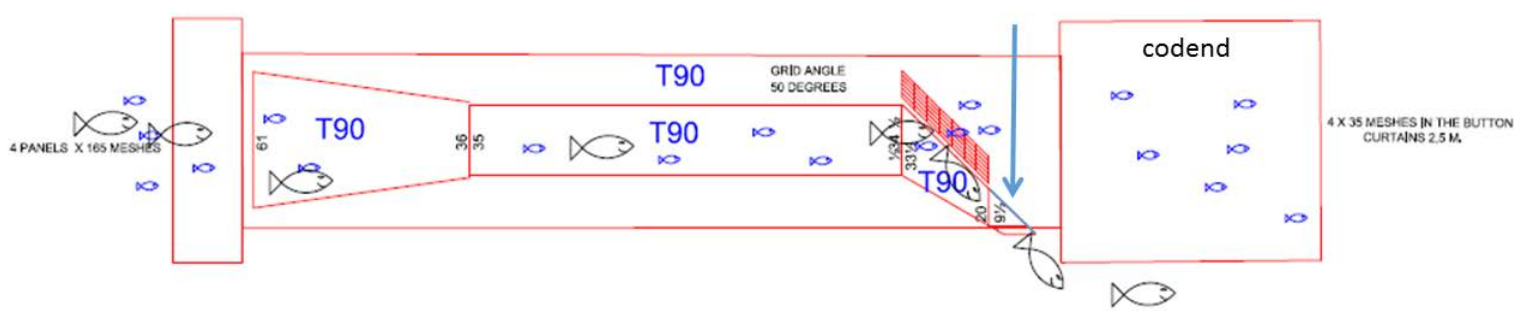

Figure 3.1 Original design of the sorting grid and tunnel by Nordsøtrawl that was attached to the codend of the pelagic trawl, the blue line (see arrow) indicates the fine mesh netting. The tunnel leads all fish to the grid where the larger hake are stopped from entering the final part of the codend and are diverted to the exit-hole while blue whiting pass the grid and enter the codend. 


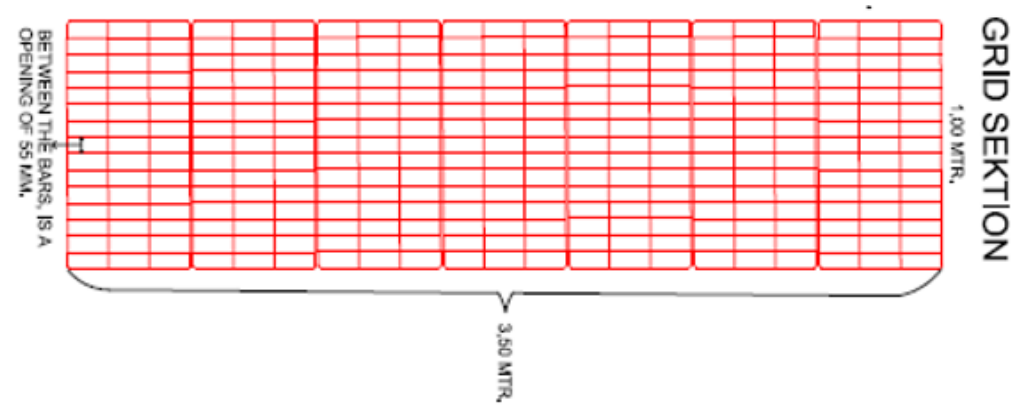

Figure 3.2 Sorting grid design by Nordsøtrawl of 1 meter wide, 3,5 meter long and the bars are spaced $5.5 \mathrm{~cm}$ apart with a height of $16 \mathrm{~cm}$. The grid is constructed from tough flexibel plastic made up of 7 sections that allow enough flexibility to wind the entire grid on the netdrum.
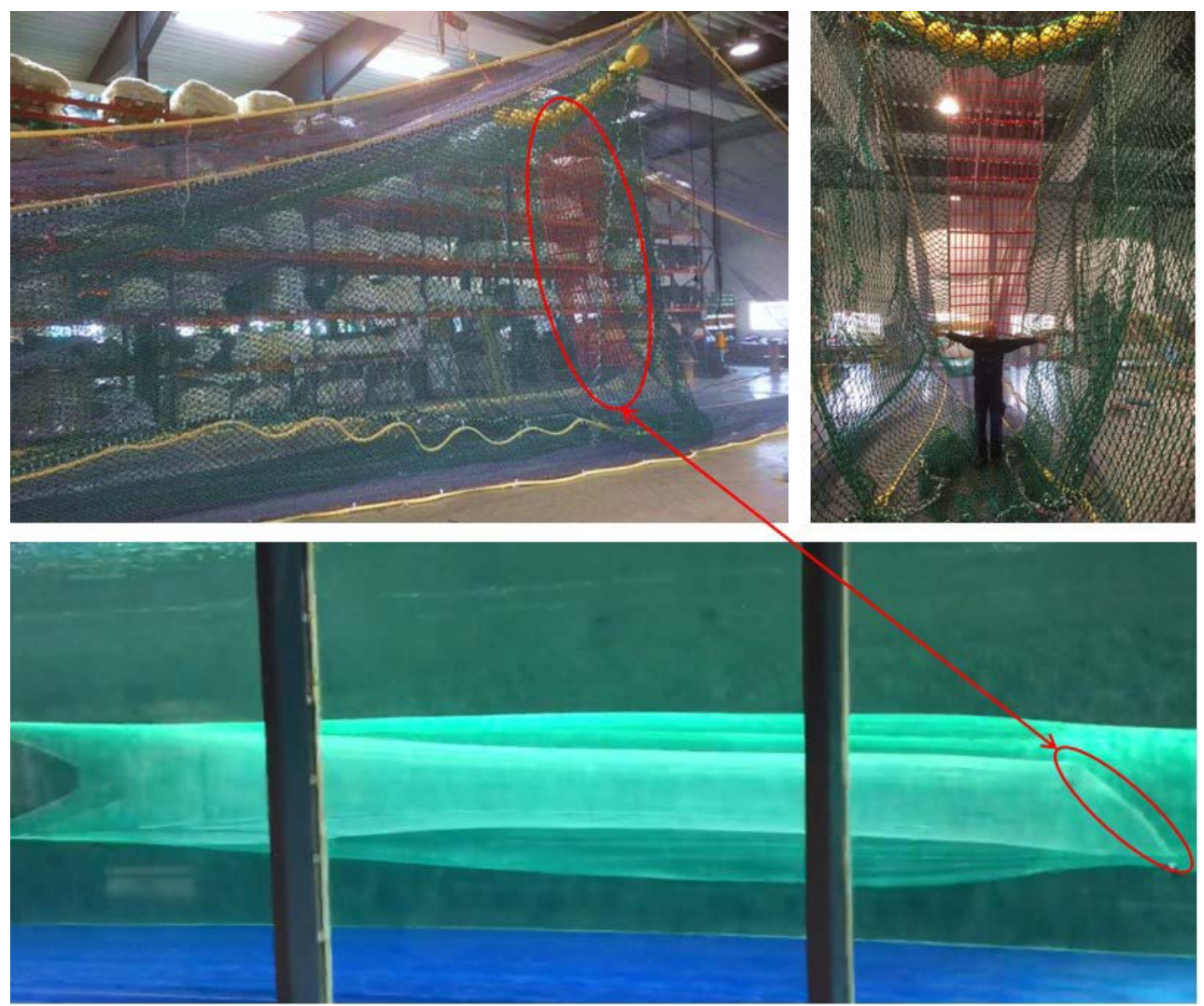

Figure 3.3 The tunnel and sorting grid pictured in the trawl from three different perspectives. The green tunnel and red grid in the codend of the pelagic trawl (top left) from a sideways perspective. The hake excluding device from the inside of the tunnel with a person for scale (top right). A scaled version was tested in the flume tank (bottom), the grid is indicated by the red ellipse. (Photo: $M$. Pastoors). 


\subsection{Camera setup}

To monitor the effectiveness of the Nordsøtrawl grid the DeepWater Camera Unit with integrated light from JT electric Ltd. was used. This camera system was placed in three locations (figure 3.4). For positions 1 and 3 the DeepWater camera was positioned 2 meter front of the grid at an angle of zero degrees. In position 2 the camera system was attached directly to the grid itself. During all hauls the light was used at maximum power (100\%).

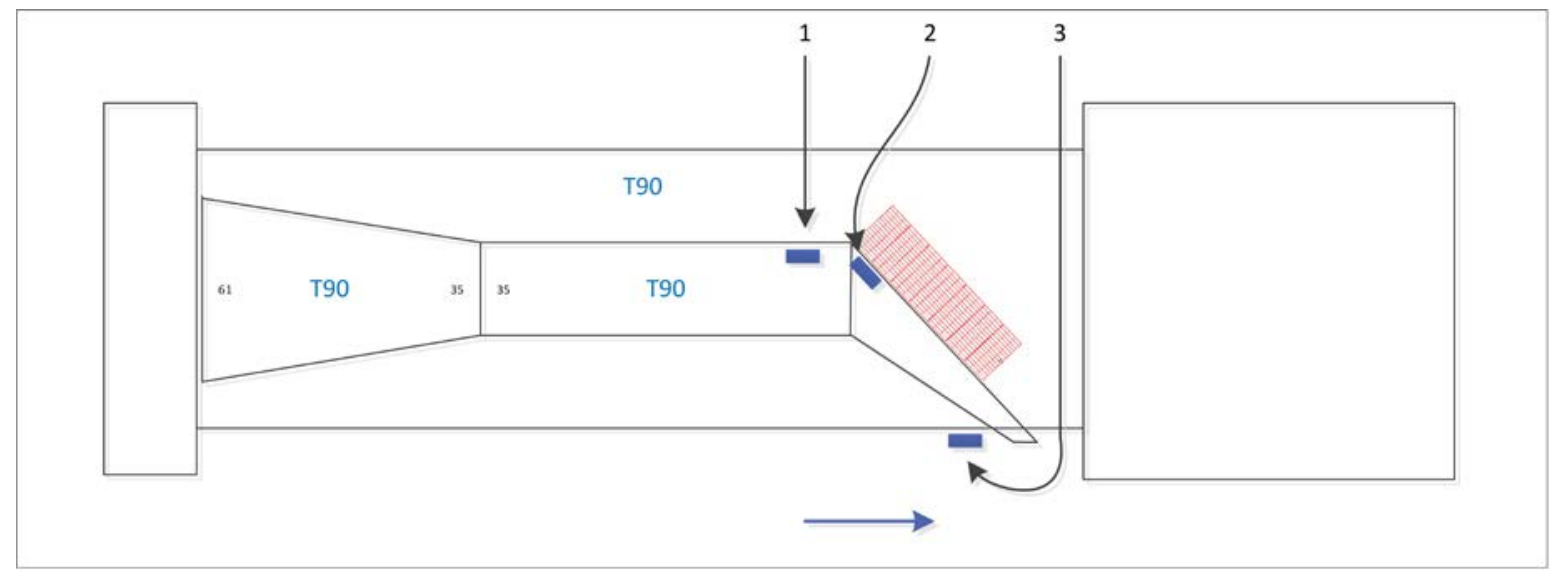

Figure 3.4 The configuration of the selective device in the trawl during the hauls. The blue rectangles indicate the three camera positions that were used seperately to observe the functioning of the grid. The camera's were all pointed towards the codend (see blue arrow).

\subsection{Field notes and other observations}

During this trip several adaptations and changes were made to increase the effectiveness of the sorting grid. Video footage was recorded to observe the effectiveness of the sorting grid during these eight hauls: $28,30,32,38,39,40,41$ and 49 . The information in this section is based on the field notes of the chief science officer of the PFA.

During the initial hauls (28 and 30) a 'pit' would form, in the fine mesh netting under the grid, that bulged out as can be seen in figure 3.5. A large quantity of fish remained trapped in this part of the tunnel, this section of the tunnel will be referred to as the 'pit' in the rest of the report. This issue was addressed by shortening this particular net section (pit) in the tunnel below the grid to improve the general water flow and avoid its trap-like effect. By shortening the pit section of the tunnel the unnecessary slack was removed.

During haul 32 it was observed that selective device did not maintain the desired position (an angle of 50 degrees) in the dyneema trawl. There was a clear improvement when using the nylon net and the selective device remained in its position much better.

During haul 38 and 39 problems with the lead-cord underneath the grid, which keeps grid in the right angle and the exit-hole open, were encountered that resulted in suboptimal performance device and large loss in catch. In haul 38 the lead-cord was not installed which caused the grid to be in a suboptimal position. During haul 39 the lead-cord was entangled and hindered the grid from fully opening. In the end kites were mounted to the top panel (figure 3.5) to further improve its position and this improvement confirmed during haul 49. This haul was carried out solely to test the position of the grid, no fishing was undertaken during this haul.

For an overview of the haul characteristics review Table 1. 


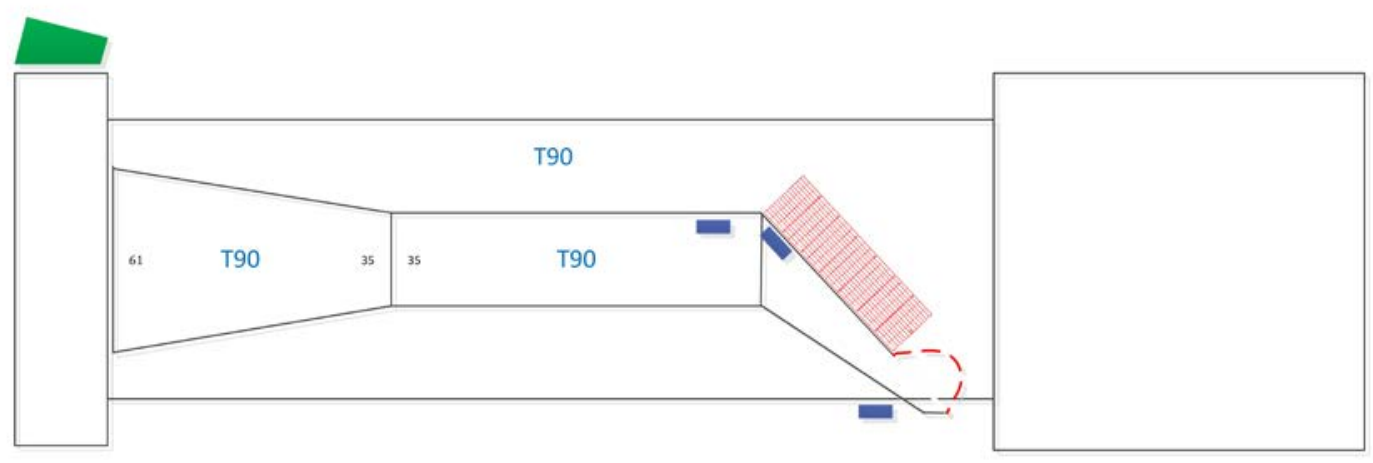

Figure 3.5 Drawing of the 'pit' below the grid, the form and location of the pit is indicated by the red doted line. The green box on the top panel marks the location of the kite that was mounted to increase the grid functioning.

Table 1 Haul specifications per trawl type and the actual camera position (see figures 3.4 and 3.6).

\begin{tabular}{lllll} 
Haul & Date & Trawl material & Tunnel \& Grid & Camera position \\
\hline 28 & $4-5-2017$ & Dyneema & Basic & 1 \\
\hline 30 & $5-5-2017$ & Dyneema & Basic & 3 \\
\hline 32 & $6-5-2017$ & Dyneema & Slack removed & 1 \\
\hline 38 & $8-5-2017$ & Nylon & Slack removed & 1 \\
\hline 39 & $8-5-2017$ & Nylon & Slack removed & 3 \\
\hline 40 & $9-5-2017$ & Nylon & Slack removed & 3 \\
\hline 41 & $9-5-2017$ & Nylon & Slack removed & 2 \\
\hline 49 & $12-5-2017$ & Nylon & Kites mounted & 1
\end{tabular}

\subsection{Manual video analysis}

The footage recorded during eight successful hauls was used to make a qualitative assessment of technical functioning of the selective device and give an insight into behaviour of fish towards the tunnel and grid.

The behaviour of hake (Merluccius merluccius), blue Whiting (Micromesistius poutassou), mackerels (Scombridae) and saithe (Pollachius virens) is described for the dyneema and nylon trawl as observed from the three (camera) positions in the trawl (see figure 3.4 and 3.6). The influence of technical adaptations (e.g. slack removed and kites mounted) on the technical functioning and the effect on the fish behaviour is also mentioned.
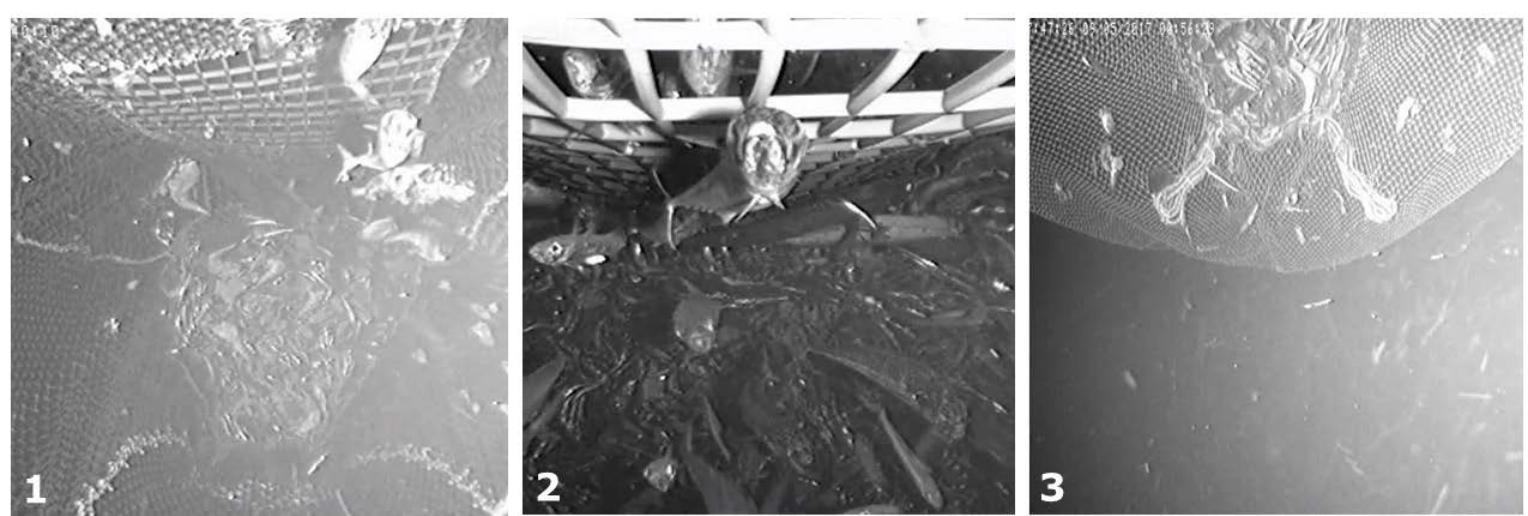

Figure 3.6 Screenshots from the camera positions 1, 2 and 3. This provides a reasonable idea what can be observed in the most optimal conditions, often the large number of fish clutter the view. 


\subsubsection{Sample selection}

Based on experience of previous video analysis work it was decided to take a sample of $10 \%$ per haul from all the footage taken during the actual fishing time. A minimum of 3 video clips were sampled per haul in order to get a reasonable sample size and idea of the characteristics of each haul and the behaviour of the fish species. The footage was stored in clips of 5 minutes each. With the randomizer function in Excel the video clips per haul were selected. For two hauls more than $10 \%$ of footage was sampled because of the minimum threshold of 3 video clips. In the case of haul 28 an additional random clip was selected because in clip 24 (H28-c24) the density of mackerels was too high to observe the behaviour of other species (Table 2 ).

\begin{tabular}{|c|c|c|c|c|c|c|c|c|c|c|}
\hline Haul & Total clips & $\begin{array}{c}10 \% \text { of total } \\
\text { no. clips }\end{array}$ & $\begin{array}{l}\text { Clips to analyse } \\
\quad(\min .=3)\end{array}$ & \multicolumn{7}{|c|}{$\begin{array}{l}\text { Sampled clips (based on } \\
\text { randomizer) }\end{array}$} \\
\hline 28 & 41 & 4.1 & 4 & 35 & 29 & 48 & 24 & 31 & & \\
\hline 30 & 72 & 7.2 & 7 & 31 & 71 & 84 & 87 & 86 & 46 & 24 \\
\hline 32 & 76 & 7.6 & 7 & 64 & 86 & 82 & 70 & 38 & 39 & 55 \\
\hline 38 & 31 & 3.1 & 3 & 34 & 35 & 38 & & & & \\
\hline 39 & 17 & 1.7 & 3 & 16 & 17 & 12 & & & & \\
\hline 40 & 29 & 2.9 & 3 & 20 & 33 & 11 & & & & \\
\hline 41 & 26 & 2.6 & 3 & 14 & 26 & 20 & & & & \\
\hline 49 & 9 & 0.9 & 3 & 11 & 12 & 17 & & & & \\
\hline & Total & 30 & 33 & & & & & & & \\
\hline
\end{tabular}

\subsubsection{Observation protocol}

I nitially the entire 5 minute clip was played without interruption to get a good overview of the situation. The uninterrupted playback allowed the observer to correctly interpret natural flow and movement of the tunnel, grid, water and fish. Afterwards the video was reviewed in more detail because often a multitude of things happen simultaneously. The knowledge of the uninterrupted playback in advance of the detailed review is helpful to make a more accurate assessment because the later constant interruptions alter the way you observe motion and the overall image.

Observations of the clip were made directly after the initial uninterrupted playback and supplemented during the detailed review. Notes were divided into general observation and species specific observations. 


\section{$4 \quad$ Results}

\subsection{Sorting grid}

The application of a tunnel with a sorting grid inside a trawl seems to have the potential to prevent unwanted hake catches. The target species, blue whiting can successfully find their way through the grid, however a substantial amount is still lost via the exit-hole. In hauls before the slack beneath the grid was removed ( $\mathrm{H} 28$ and $\mathrm{H} 30$ ) and during the haul ( $\mathrm{H} 38$ and $\mathrm{H} 39$ ) with the entangled lead-cord the pit was a large obstacle to overcome for the fish and water flow. It seems that therefore it was more difficult to escape and potentially less likely to find the grid. After these adjustments the orientation of the grid and tunnel was better, although still suboptimal. Even though difficult to judge from the video footage, based on observation of the water flow and subsequent swimming orientation of the fish (figure 4.1), it seemed that the grid's orientation was nearly horizontal. Even after subsequent adjustments a large pit remained at the far end of the tunnel (depicted with the red dotted line in figure 4.2). From the footage of haul 38 and 41 it is clear that there is slack in the tunnel that form pouch-like parts (figure 4.1) on both sides of the grid, which act as a 'trap' for several hake. Kites were added to the top panel during haul 49 and this improved the general tension in the tunnel but the angle of the grid was still not sufficient.
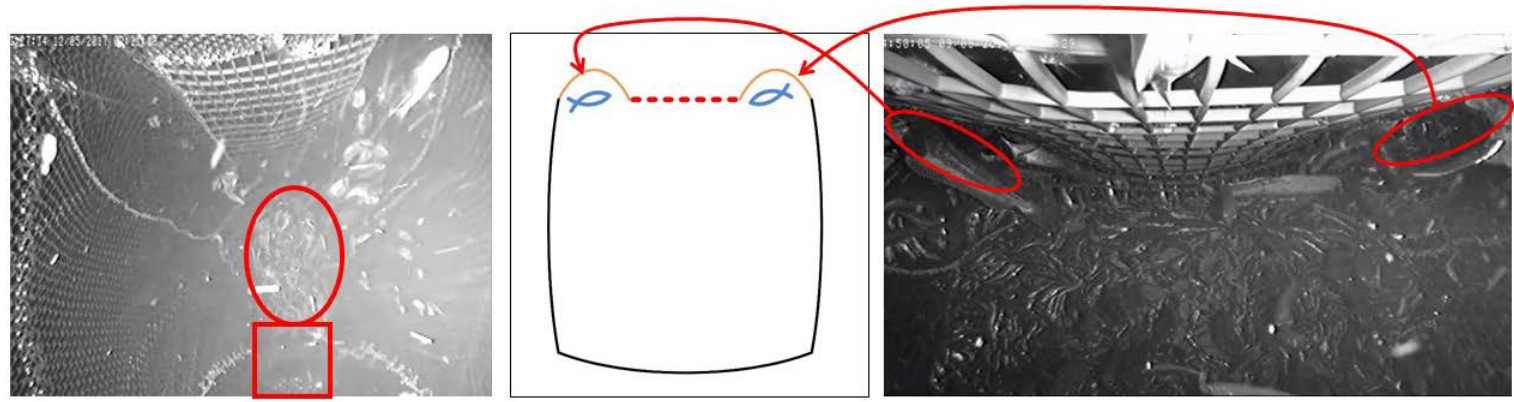

Figure 4.1 The nearly horizontally oriented grid (left) with the pit in the background (red ellipse) and the exit-hole below (red square). The pouch-like parts are displayed in a crosssection of the tunnel (middle) and a screenshot (right) from the videos. In the crosssection the red dotted line indicates the grid and the orange half circles the pouches that catch hake. On the right the red ellipses indicate the pouch-like parts of the trawl, in the image right a hake is about the get stuck in the pouch.

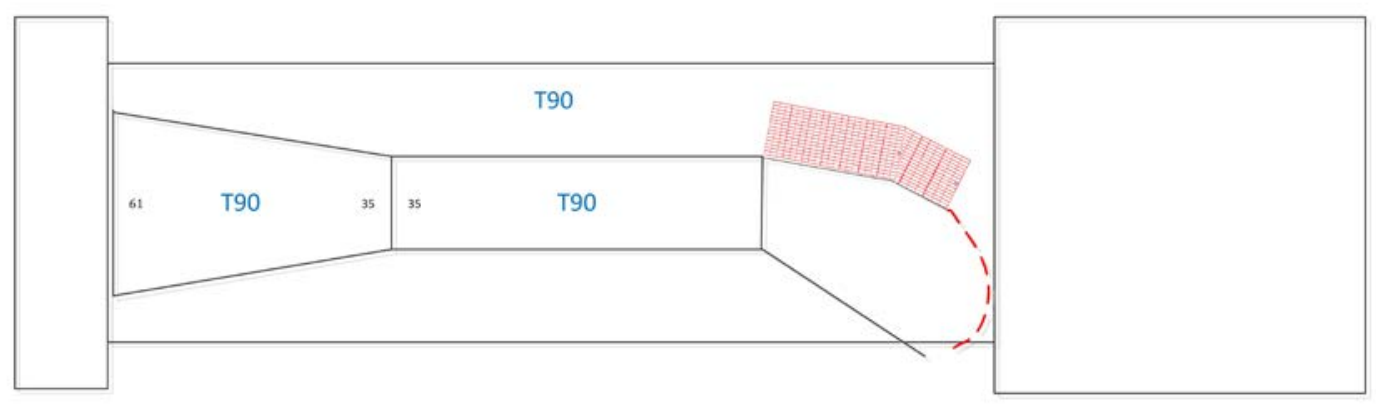

Figure 4.2 Schematic overview of the situation as interpreted from the video footage with a nearly horizontally oriented grid and a large pit on the back end of the tunnel. 


\subsection{Hake (Merluccius merluccis)}

Based on the reviewed footage it was observed that most hake undertook several weak attempts at escaping, mostly in a sideways trajectory, ranging from weak tail trusts to stronger bursts of speed. In general, larger specimens appear to have more energy and endurance than smaller individuals, in some cases even fighting the water flow for some time to remain in the tunnel. Nevertheless, in general they quickly get stuck in the tunnel netting and surrender to the water flow. Some of the more energetic individuals bounce around from side to side until they get stuck or find their way towards the exit-hole and disappear from the field of view of camera. A large number of individuals from all sizes get stuck in the netting on the sides of the grid. This is in particular the case in the pouch-like parts as in paragraph 4.1. It was observed that hake has difficulties locating the exit-hole even in situations were individuals had enough energy to move around.

It seems that hake surrenders instantly when their sides touch the net. Probably, they are stuck in this position, because the lack of strength to overcome the pressure of the water flow on the lateral sides of the body. Specimens are only 'escaping' a net-encounter when their head hits it, provided that they do not get snagged behind the gills.
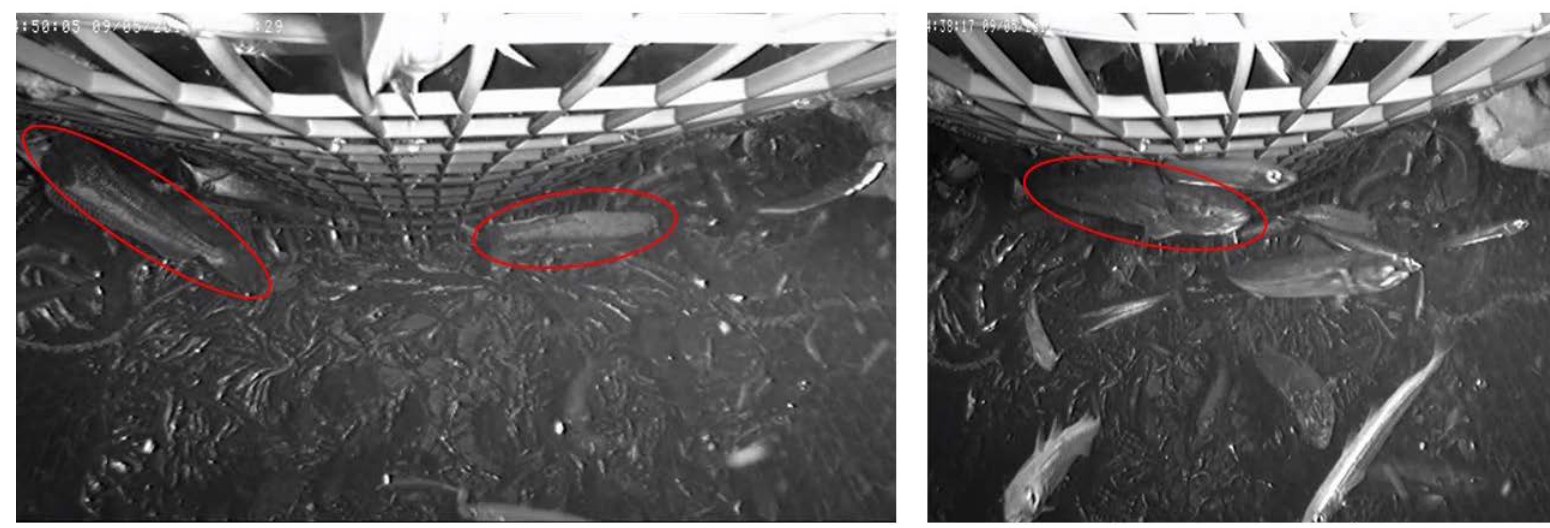

Figure 4.3 Many hake get stuck in the tunnel of the selective device (left) while others seem to find their way to the exit-hole (right).

\subsection{Blue whiting (Micromesistius poutassou)}

Whiting are capable of maintaining position by swimming against the water flow for a short amount of time. Though with increased water flow velocity there is less control, and consequently less control in their escape attempts. Similarly, a decrease in the ability to controlling/maintaining their position was observed when the abundance of fish in the net increased, in other words: they are less able to control their location in the water column as they drift along with the masses. Especially in these situations large numbers of blue whiting would exit the trawl via the exit-hole. It was observed regularly that individuals passed the grid or bounced off the grid, net or pit several times without getting stuck. From observations of camera positions 1 and 2 (Figure 3.4) it became clear that specimens their likelihood of going through the grid, or exit-hole, is related to their positions in the tunnel (low/high). Fish that are positioned low in the tunnel (at the bottom of the tunnel/trawl) are most likely drift towards the exit-hole without encountering the grid. Fish that are positioned high in the tunnel (near the ceiling of the trawl) have the greatest chance of drifting towards the grid and passing it. 


\subsection{Mackerels (Scombridae)}

Mackerels are strong swimmers and swim against the water flow, both in and outside the trawl. Often they appear to be attracted by the video light but in lower densities (less fish abundant) this effect is less. It was observed that in low abundance several individuals simply swim away when they exit the exit-hole. In some instances mackerels were swimming back and forth between the grid. It seems that mackerels sometimes prefer locations with strong water flow.

\subsection{Saithe (Pollachius virens)}

This strong swimmer is in full control of its position and is observed swimming into the current alongside with mackerels until it was lost from the field of view of the camera. They were capable of finding their way out the trawl via the exit-hole in large numbers when the trawl was hauled. 


\section{$5 \quad$ Conclusions and recommendations}

Potentially, this selective device can be an effective tool to avoid the by-catch of hake. Based on the field observations of the chief science officer the amount of hake by-catch reduced after the selective device was installed. In addition, video review of underwater footage confirmed that large hake did not pass the grid and individuals successfully escaped. However, based on the video review, it is obvious that the sorting grid, including the tunnel construction, needs to be optimized with regards to the escapability of hake and retainment of blue whiting. Lots of hake did not escape and got stuck. Because, only one camera was available, it was not possible to record multiple positions in the tunnel simultaneously and, consequently, it was impossible to get a complete overview of escape success in a haul. As a consequence, no direct comparison could be made between the numbers of hake stuck in the tunnel and the number of individuals that did escape. Aside from hake entanglement another potential problem was the loss (the number of escapements) of the target species, blue whiting. Both mackerels and saithe were observed to exit the trawl successfully through the exit-hole. Mackerels were also observed to go back and forth trough the grid.

Blue whiting is capable of controlled swimming and are able to avoid entanglement provided that the water flow is relatively slow and abundance of fish in the tunnel is low. When fish abundance in the tunnel increases behaviour of blue whiting changes and individuals are more likely to drift wherever the water flow takes them, in case of these trials this is often towards the exit-hole instead of the sorting grid. To decrease the loss of blue whiting when large numbers of fish pass through the trawl or their positioned low in the tunnel/trawl, the position of blue whiting in the tunnel should be manipulated in a way that it 'forces' blue whiting towards the grid. However, because hake requires a smooth unobstructed path to the exit-hole with a water flow to lead them there, the creation of water flow towards the grid could have a negative effect on the escapement of hake. To benefit from the difference in the behaviour of hake and blue whiting, multiple loose floating ropes/strings in grid section of the tunnel (figure 5.1) could be added. This could be enough of a stimulus for blue whiting to swim away and therefore move more towards the grid and hake will most likely pass by these ropes passively. If the addition of floating ropes is not sufficient to 'force' blue whiting towards the grid, a guiding panel could be installed (figure 5.1) and tested. Provided that hake have a completely unobstructed and smooth path to the exit-hole.

As seen in the footage the pit and pouches around the grid form a trap for the hake. To create an unobstructed path for the hake it would be advisable to avoid pouch and pit forming. The pouches could have been caused by the weight of the Deepwater camera that pulled the grid down or it can be a construction defect. In case of the later, this can be solved by extending the grid in multiple directions, longer and wider, or adjust the tunnel specifications so it is tapered towards the grid (figure 5.1). To improve the efficiency of the grid, it is also recommended to keep the sorting grid at the intended angle (an angle of 50 degrees), during video analysis it was observed the grid was in almost horizontal position. 


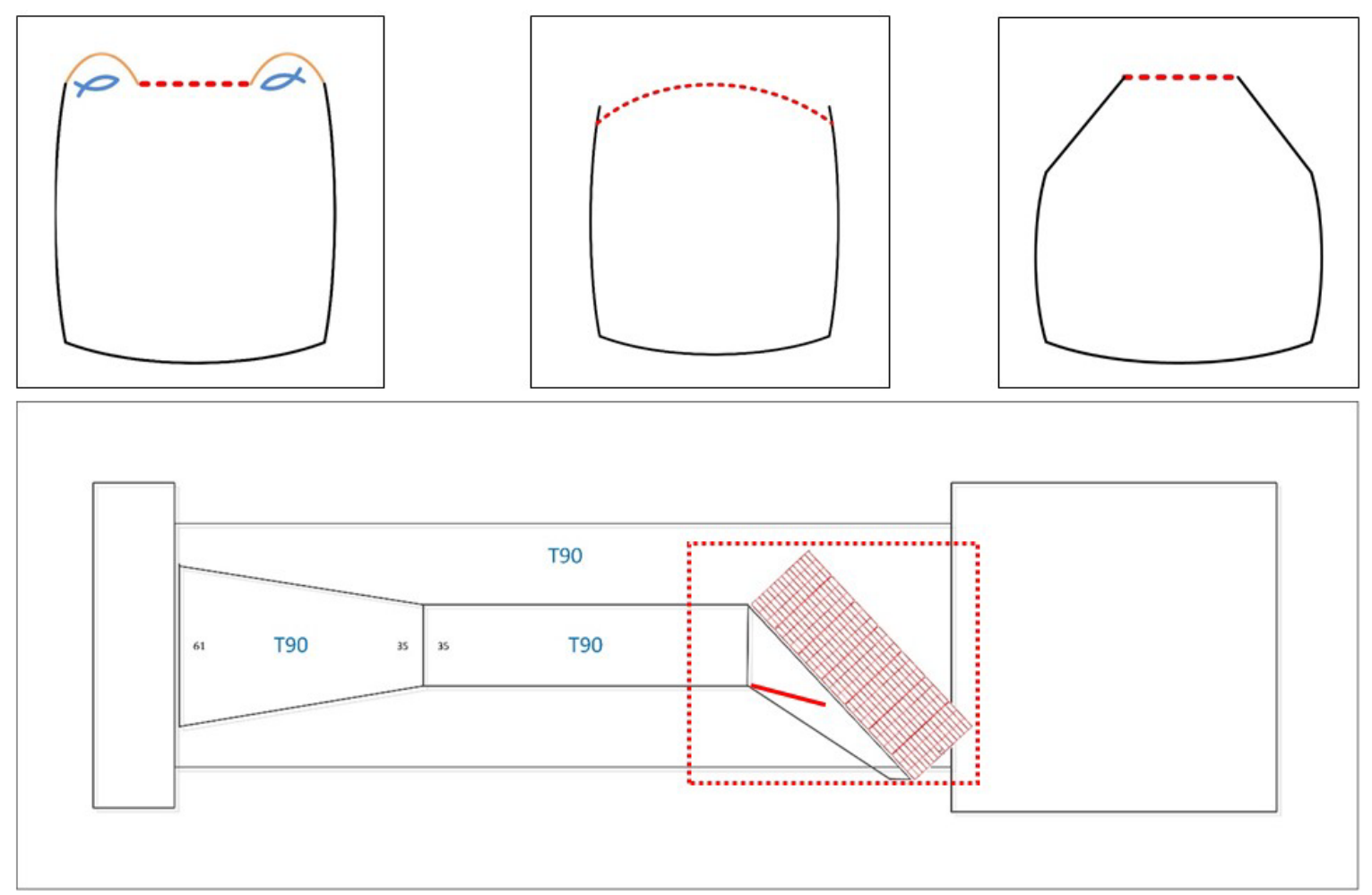

Figure 5.1 The old cross-section (left above) shows the problematic pouches and the new design (middle above) could solve this by widening the grid (red dotted line) or tapering the top side of the tunnel (right above). By extending the grid all the way to the end of the tunnel (below) the issue with the pit could be resolved. The thick red line (below) indicates the location for the loose floating lines or the guiding panel in grid section of the tunnel. 


\section{Quality Assurance}

Wageningen Marine Research utilises an ISO 9001:2008 certified quality management system (certificate number: 187378-2015-AQ-NLD-RvA). This certificate is valid until 15 September 2018. The organisation has been certified since 27 February 2001. The certification was issued by DNV Certification B.V.

Furthermore, the chemical laboratory at IJ muiden has NEN-EN-ISO/IEC 17025:2005 accreditation for test laboratories with number L097. This accreditation is valid until $1^{\text {th }}$ of April 2021 and was first issued on 27 March 1997. Accreditation was granted by the Council for Accreditation. The chemical laboratory at IJ muiden has thus demonstrated its ability to provide valid results according a technically competent manner and to work according to the ISO 17025 standard. The scope (L097) of de accredited analytical methods can be found at the website of the Council for Accreditation (www.rva.nl).

On the basis of this accreditation, the quality characteristic $\mathrm{Q}$ is awarded to the results of those components which are incorporated in the scope, provided they comply with all quality requirements. The quality characteristic $\mathrm{Q}$ is stated in the tables with the results. If, the quality characteristic $\mathrm{Q}$ is not mentioned, the reason why is explained.

The quality of the test methods is ensured in various ways. The accuracy of the analysis is regularly assessed by participation in inter-laboratory performance studies including those organized by QUASIMEME. If no inter-laboratory study is available, a second-level control is performed. In addition, a first-level control is performed for each series of measurements.

In addition to the line controls the following general quality controls are carried out:

- Blank research.

- Recovery.

- Internal standard

- Injection standard.

- Sensitivity.

The above controls are described in Wageningen Marine Research working instruction ISW 2.10.2.105. If desired, information regarding the performance characteristics of the analytical methods is available at the chemical laboratory at IJ muiden.

If the quality cannot be guaranteed, appropriate measures are taken. 


\section{J ustification}

Report C080/17

Project Number: 43.111.000.56

The scientific quality of this report has been peer reviewed by a colleague scientist and a member of the Management Team of Wageningen Marine Research

Approved: Ir. J. Steenbergen

Researcher

Signature:

Date:

$13^{\text {th }}$ of October 2017

Approved:

Dr. ir. T.P. Bult

Director

Signature:

Date:

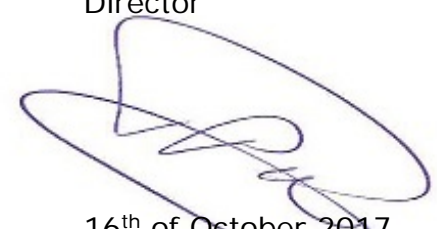

$16^{\text {th }}$ of October 2017 
Wageningen Marine Research

T +31 (0)317 480900

E: marine-research@wur.nl

www.wur.eu/marine-research

Visitors' address

- Ankerpark 7, 1781 AG Den Helder

- Korringaweg 5, 4401 NT Yerseke

- Haringkade 1, 1976 CP IJ muiden
Wageningen Marine Research is the Netherlands research institute established to provide the scientific support that is essential for developing policies and innovation in respect of the marine environment, fishery activities, aquaculture and the maritime sector.

\section{Wageningen University \& Research:}

is specialised in the domain of healthy food and living environment.

\section{The Wageningen Marine Research vision}

'To explore the potential of marine nature to improve the quality of life'

\section{The Wageningen Marine Research mission}

- To conduct research with the aim of acquiring knowledge and offering advice on the sustainable management and use of marine and coastal areas.

- Wageningen Marine Research is an independent, leading scientific research institute

Wageningen Marine Research is part of the international knowledge organisation Wageningen UR (University \& Research centre). Within Wageningen UR, nine specialised research institutes of the Stichting Wageningen Research Foundation have joined forces with Wageningen University to help answer the most important questions in the domain of healthy food and living environment. 